\title{
Parâmetros bioquímicos de equinos submetidos à simulação de prova de enduro recebendo dietas com adição de óleo de soja
}

\section{Roberta Ariboni Brandi ${ }^{1^{*}}$, Carlos Eduardo Furtado ${ }^{2}$, Elias Nunes Martins ${ }^{2}$, Eduardo Villela Villaça Freitas ${ }^{3}$, Antônio de Queiroz-Neto ${ }^{4}$, José Corrêa de Lacerda-Neto ${ }^{4}$}

\author{
1 Pós-graduanda-PPZ/UEM. \\ 2 Departamento de Zootecnia, Universidade Estadual de Maringá. \\ 3 Pós-graduando UNESP/Jaboticabal. \\ ${ }^{4}$ Faculdade de Ciências Agrárias e Veterinárias - UNESP/Jaboticabal.
}

RESUMO - Com o objetivo de verificar o efeito da adição de níveis crescentes de óleo no concentrado sobre a atividade plasmática das enzimas creatina quinase (CK), aspartato aminotransferase (AST) e lactato desidrogenase (LDH) como indicativo de metabolismo energético, foram fornecidas dietas experimentais compostas de cinco níveis de óleo (controle, 6, 12, 18 e 24\% do concentrado). Utilizaram-se 20 equinos da raça Árabe, peso médio de $400 \mathrm{~kg}$, submetidos a prova de enduro de $80 \mathrm{~km}$ em esteira rolante. O enduro foi dividido em quatro anéis de $20 \mathrm{~km}$, com duração média de 1 hora e dez minutos. A adição de óleo e a distância percorrida tiveram efeitos sobre as variáveis AST, CK e LDH, que apresentaram as respectivas expressões: AST $(7,045-0,2292 x+0,007991 x 2+0,008517 z-0,0003282 x z)$, CK $(8,06-, 07020 x+0,05546 x 2-$ $0,001262 \times 3+0,01204 z+0,0006207 x z)$ e LDH $(6,624-0,3522 x+0,03448 \times 2-0,0008382 \times 3+0,02401 z-0,0007489 x z)$. O óleo é uma importante e bem aproveitada fonte de energia para equinos em exercício, pois sua adição na dieta de animais submetidos a prova de enduro promoveu alteração metabólica que favorece a produção de energia. O metabolismo animal poupou suas reservas energéticas oriundas da glicose, favorecendo a utilização do óleo. A menor atividade plasmática das enzimas AST, CK e LDH com a adição de óleo nas dietas indica direcionamento do metabolismo energético para a $\beta$-oxidação. Como apresentam várias isoenzimas, as enzimas estudadas atuam amplamente no metabolismo energético, favorecendo a constante reposição de ATP ao longo do exercício.

Palavras-chave: $\beta$-oxidação, cavalo, desempenho, energia, óleo

\section{Biochemical parameters of horses submitted to an endurance simulation receiving diets with soybean oil addition}

\begin{abstract}
The objective of this study was to verify the effect of increasing soybean oil addition levels in the concentrate, on the enzymatic activity CK (Creatine Kinase), LDH (Lactate Dehydrogenase), AST (Astarte aminostrafase) as an indication of energetic metabolism. Compond experimental diets were given with five oil levels (control, 6, 12, 18 and 24\% concentrate). Twenty Arabian equines, average weight $400 \mathrm{~kg}$ were submitted to a $80 \mathrm{~km}$ endurance race on a treadmill. The endurance was divided into four $20 \mathrm{~km}$ rings with an average duration of one hour and 10 minutes. A significant effect of oil addition and the covered distance was observed on the variables AST, CK, LDH and they present the respective expressions AST and $(7,045-0,2292 x+0,007991 x 2+0,008517 z-0,0003282 x z)$ CKand $(8,06-, 07020 x+0,05546 \times 2-$ $0,001262 \times 3+0,01204 z+0,0006207 x z)$, LDH and $(6,624-0,3522 x+0,03448 \times 2-0,0008382 \times 3+0,02401 z-0,0007489 x z)$. The oil is an important and well-used energy source for horses in exercise, because its addition to the diet of animals submitted to endurance test cause metabolic alteration that favored energy production. The animal metabolism save its energy reserves derived from glucose and favored the use of the oil. The smaller plasmatic activity of the AST, CK and LDH, enzymes with the addition of oil to the diets indicated directioning of the energy metabolism to $\beta$-oxidation. As the enzymes show several isoenzymes, it was concluded that the enzymes studied act widely on the energetic metabolism, favoring constant ATP reposition during all exercise.
\end{abstract}

Key Words: $\beta$-oxidation, energy, horse, oil, performance

Recebido em 17/8/2007 e aprovado em 20/2/2009

Correspondências devem ser enviadas para: robertabrandi@usp.br

*Endereço atual: FZEA/USP - Av. Duque de Caxias Norte, 225 - Campus da USP - CEP :13635-900 - Pirassununga,SP. 


\section{Introdução}

O fornecimento de óleo na dieta de equinos promove, em conjunto com o treinamento, uma série de adaptações orgânicas no animal, favorecendo a utilização de lipídios. Segundo Frape (1994), os cavalos devem ser adaptados a dietas com óleo durante 6 a 11 semanas para utilização no metabolismo muscular e 21 dias para adaptação do trato digestório (Bray \& Wickler, 1997).

A inclusão de óleo na dieta deve ser aliada ao correto treinamento aeróbico (Pagan et al., 1995). Os lipídios constituem-se alternativa de fornecimento energético $(2,25$ vezes mais concentrado que o amido) para cavalos de enduro. Vários estudos comprovam efeitos benéficos da adição de óleo na dieta, como maior mobilização e utilização de gorduras (Pagan et al., 1987) e efeito poupador de glicogênio. A utilização de óleo nesta atividade permite fornecer uma dieta mais energética, diminuindo a quantidade do concentrado a ser fornecida e prevenindo distúrbios metabólicos graves, como cólicas, laminite e rabdomiólise.

A primeira fonte energética é a creatinafosfato, que gera creatina e é catalisada pela creatina quinase (CK), constituindo-se no primeiro processo para suprir a demanda de adenosina trifosfato (ATP) durante os dez primeiros segundos do exercício (Baldissera, 1997). Após esse período, a energia é gradualmente transferida para a fosforilação oxidativa, a qual é expressa pela intensificação no consumo de oxigênio.

A atuação da creatina quinase muscular e total é maior nas fibras do tipo IIB (Yamashita \& Yoshioka,1991), enquanto a atividade da creatina quinase mitocondrial é maior na fibra do tipo I. Segundo Bendahan et al. (2003), a creatina fosfato pode ser usada também como tampão.

Auxiliando na manutenção da relação de NADH:NAD atua a enzima aspartato aminotransferase (AST), que atua diretamente na lançadeira de malato (Harper, 1977).

A enzima lactato desidrogenase (LDH) apresenta isoenzimas com diferentes combinações peptídicas: $\mathrm{H}$ (coração) e M (muscular). A remoção de lactato pela oxidação é facilitada quando se combinam tecidos com alta irrigação e elevada porcentagem de H-LDH (Favero et al., 1999).

O objetivo neste trabalho foi verificar o efeito da adição de níveis crescentes de óleo de soja à dieta de equinos submetidos a prova de enduro em esteira rolante $(80 \mathrm{~km})$ sobre a atividade plasmática das enzimas CK, AST e LDH como indicativo de metabolismo energético.

\section{Material e Métodos}

Foram utilizados 20 equinos da raça Árabe, machos e fêmeas, com 9,5 \pm 5,5 anos de idade e peso vivo de $400 \pm$ $29,1 \mathrm{~kg}$, treinados para simulação de prova de enduro de $80 \mathrm{~km}$ em esteira rolante. Todos os animais selecionados para o experimento estavam em repouso e não foram submetidos a nenhum tipo de treinamento antes do início do período experimental.

O experimento teve duração de 48 dias, período no qual os animais foram alojados em baias de alvenaria de $9 \mathrm{~m}^{2}$, providas de cama de maravalha, comedouro e bebedouro, localizadas no Setor de Equinocultura do Departamento de Zootecnia da Faculdade de Ciências Agrárias e Veterinárias, Universidade Estadual Paulista, Jaboticabal (FCAV-UNESP/ Jaboticabal).

Durante os primeiros 15 dias, os animais foram adaptados às dietas experimentais, formuladas segundo o NRC (1989) para cavalos de esporte de média intensidade com demanda energética de 20,1 Mcal e demanda proteica de $804 \mathrm{~g}$.

As dietas experimentais foram compostas de cinco concentrados formulados com adição de $0,6,12$, 18 ou $24 \%$ de óleo de soja e feno de capim-tifton 85 , mantendo-se a respectiva relação de 50:50 (Tabelas 1 e 2). Desta forma forneceram-se $2,6 \mathrm{~kg}$ de feno (10,5 Mcal) e aproximadamente 2,$5 ; 2,4 ; 2,37,2,1$ e $2,0 \mathrm{~kg}$ de concentrado nas dietas com 0 ; 6; 12; 18 e 24\% de óleo no concentrado, perfazendo a demanda de 20,1 Mcal. As variações na quantidade fornecida foram atribuídas às diferenças no peso dos animais, uma vez que as dietas foram calculadas individualmente para cada animal. As dietas foram fracionadas em três refeições diárias, fornecidas às $7 \mathrm{~h}, 12 \mathrm{~h}$ e $17 \mathrm{~h}$.

Tabela 1 - Composição dos concentrados experimentais (\% MS)

\begin{tabular}{|c|c|c|c|c|c|}
\hline \multirow[t]{2}{*}{ Ingrediente } & \multicolumn{5}{|c|}{ Nível de óleo de soja na dieta } \\
\hline & Controle & $6 \%$ & $12 \%$ & $18 \%$ & $24 \%$ \\
\hline Milho grão & 84,45 & 73,65 & 60,15 & 48,1 & 38,85 \\
\hline Farelo de soja & 13,2 & 17,75 & 25 & 30,75 & 34,0 \\
\hline Óleo de soja & 0 & 6,0 & 12,0 & 18,0 & 24,0 \\
\hline Fosfato bicálcico & 0,2 & 0,3 & 0,4 & 0,65 & 0,65 \\
\hline Calcário & 0,95 & 1,0 & 1,05 & 1,0 & 1,0 \\
\hline Sal comum & 1,0 & 1,1 & 1,2 & 1,3 & 1,3 \\
\hline Suplemento mineral ${ }^{1}$ & 0,1 & 0,1 & 0,1 & 0,1 & 0,1 \\
\hline Suplemento vitamínico ${ }^{2}$ & 0,1 & 0,1 & 0,1 & 0,1 & 0,1 \\
\hline
\end{tabular}

${ }^{1}$ Suplemento mineral: P - 72 g; Ca - 191 g; Na - 68,25 g; Cl - 105 g; Mg - 27,5 g; S - 4,963 g; Zn - 1500,00 mg; Cu - 250,00 mg; Mn - 1000,00 mg; Fe - 1000,00 mg; Co - 12,24 mg; I - 20,00 mg; Se - 2,25 mg; Fl (Max) - 0,72 mg.

2 Suplemento vitamínico: vit. A - 1.600 .000 UI; vit. D3 - 200.000 UI; vit. E 3.000 UI; vit. K3 - 636 mg; vit. B1 - 1.200 mg; vit. B2 - 1.600 mg; vit. B12- 3300 mg; ácido pantotênico - $3.300 \mathrm{mg}$; biotiona $20 \mathrm{mg}$; ácido nicotínico - $6.000 \mathrm{mg}$; ácido fólico - $200 \mathrm{mg}$; colina - $40 \mathrm{mg}$; L-lisina - $25 \mathrm{mg}$; antioxidante - $200 \mathrm{mg}$. 
Tabela 2 - Composição nutricional do feno de capim-tifton (\% MS )

\begin{tabular}{|c|c|c|c|c|c|c|c|}
\hline \multirow[t]{2}{*}{ Nutriente } & \multicolumn{7}{|c|}{ Nível de óleo de soja na dieta } \\
\hline & Controle & $6 \%$ & $12 \%$ & $18 \%$ & $24 \%$ & Feno & capim-tifton \\
\hline Matéria seca (\%) & 93,12 & 94 & 89 & 90,2 & 91,25 & & 91,0 \\
\hline Proteína bruta (\%) & 14,06 & 14,86 & 15,45 & 17,83 & 18,78 & & 9,95 \\
\hline Fibra em detergente neutro $(\%)^{1}$ & 13,94 & 13,3 & 13,4 & 12,9 & 11,9 & & 85,2 \\
\hline Fibra em detergente ácido $(\%)^{1}$ & 3,44 & 3,74 & 4,02 & 4,85 & 5,51 & & 43,02 \\
\hline Matéria mineral (\%) & 4,0 & 4,0 & 3,0 & 5,0 & 5,0 & & 5,5 \\
\hline Extrato etéreo (\%) & 3,52 & 8,8 & 10,6 & 19,7 & 22,73 & & 1,0 \\
\hline Energia bruta (kcal/kg) & 4213,0 & 4386,0 & 4436,0 & 4996,0 & 5235,0 & & 4102,0 \\
\hline \multicolumn{8}{|c|}{ Composição nuticional das dietas experimentais (relação concentrado:volumoso 50:50) } \\
\hline Matéria seca (\%) & 92,06 & 92,5 & 90,0 & 90,6 & 91,125 & & \\
\hline Proteína bruta (\%) & 12,005 & 12,405 & 12,7 & 13,89 & 14,37 & & \\
\hline Fibra em detergente neutro (\%) & 49,57 & 49,25 & 49,3 & 49,05 & 48,55 & & \\
\hline Fibra em detergente ácido (\%) & 22,73 & 22,89 & 23,52 & 23,94 & 22,77 & & \\
\hline Matéria mineral (\%) & 4,75 & 4,75 & 4,25 & 5,25 & 5,25 & & \\
\hline Extrato etéreo (\%) & 2,26 & 4,9 & 5,8 & 10,35 & 11,87 & & \\
\hline Energia bruta (kcal/kg) & 4157,5 & 4244,0 & 4269,0 & 4549,0 & 4668,5 & & \\
\hline
\end{tabular}

O treinamento teve duração de 48 dias, com base no limiar anaeróbico, e foi determinado individualmente pelo método do limiar anaeróbico individual (Baldari et al., 2000), amplamente utilizado tanto no homem quanto em animais, que baseia no ponto em que o equilíbrio dinâmico entre a produção e a remoção do lactato deixa de existir, por excesso de produção, e a concentração plasmática do lactato começa a crescer exponencialmente. Desta forma, o animal é submetido a protocolos de treinamento que permitam aumentar o tempo de persistência no exercício, aumentando o período em exercício para atingir a concentração crítica de lactato, peculiar a cada animal.

Ao final do $48^{\circ}$ dia, os animais foram avaliados em enduro em esteira rolante no Laboratório de Fisiologia do Exercício do Departamento de Morfologia e Fisiologia Animal, da FCAV-UNESP/Jaboticabal. A cada dia, dois animais foram avaliados, seguindo a mesma sequência de introdução no protocolo experimental, garantindo que todos os animais tivessem 48 dias de treinamento e adaptação à dieta. $\mathrm{O}$ enduro foi dividido em quatro anéis de 20 km, com duração média de 1 hora e dez minutos, de modo que somente o primeiro e terceiro anéis apresentaram inclinação (10\%) da esteira (Tabela 3). Dentro de cada anel, o animal foi submetido a ciclos de exercício seguindo o conceito de produção e remoção de lactato sugerido pelo método do lacmim (Tegtbur et al., 1993). A temperatura no interior do laboratório foi mantida em torno de $23^{\circ} \mathrm{C}$ com a ajuda de aparelho de ar condicionado e a umidade ficou em torno de $65 \%$ e foi mantida por meio de abertura e fechamento das portas da sala. A umidade foi influenciada pelo meio externo, pois, em dias de chuva e com o desenvolver da prova de enduro em esteira rolante, atingiu até $85 \%$ no interior da sala.
Tabela 3 - Anéis da prova de enduro

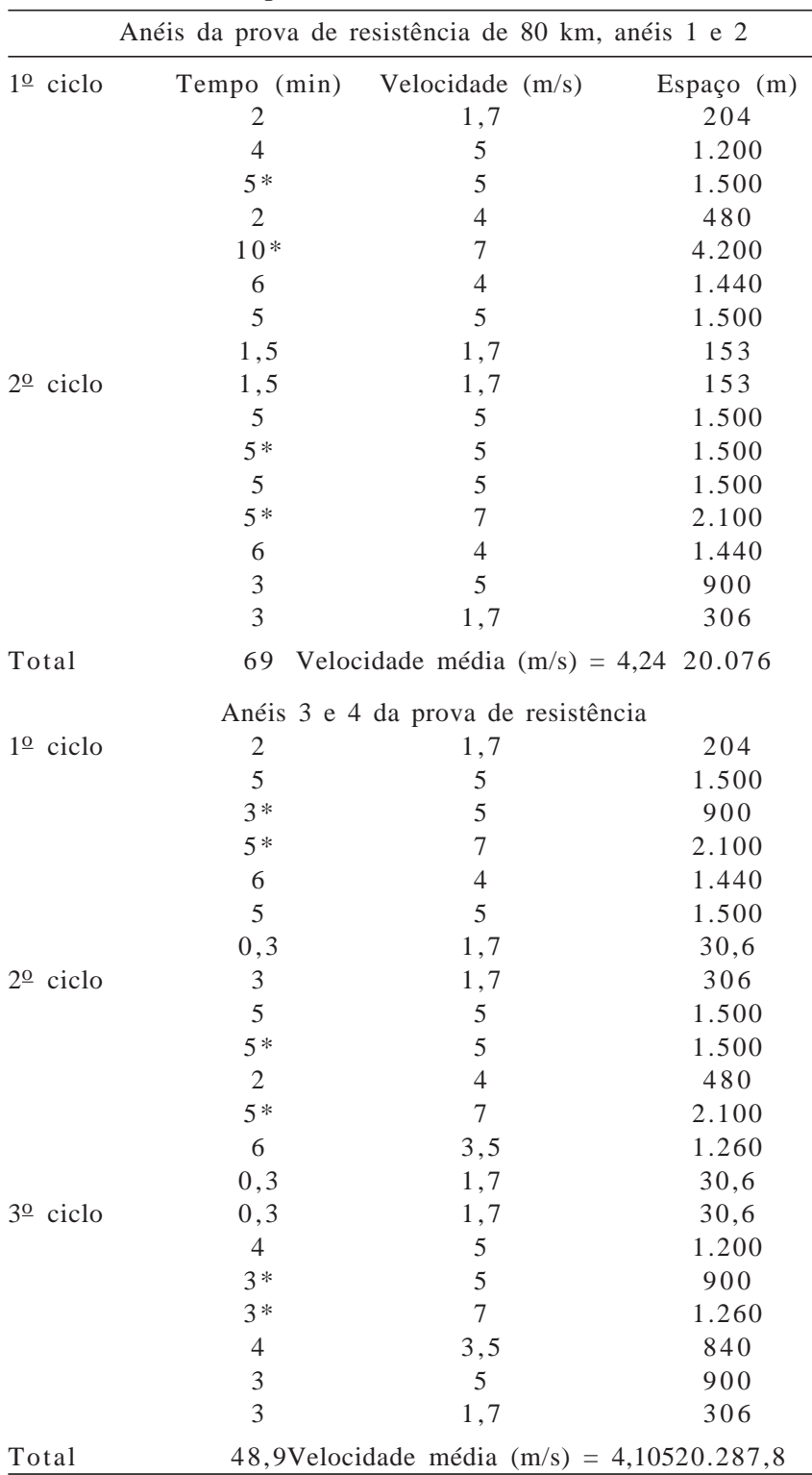

*Esteira com $10 \%$ de inclinação. 
Imediatamente depois de cada anel, foi aferida a frequência cardíaca (FC), utilizando-se estetoscópio. O animal com frequência cardíaca igual ou inferior a 60 batimentos por minuto (bat/min) foi retirado da esteira, resfriado e em um prazo máximo de 20 minutos foi submetido a exame veterinário. Neste exame o animal foi analisado clinicamente, com avaliação comportamental (vivacidade/ apatia), avaliação clínica (frequência cardíaca, frequência respiratória, tempo de preenchimento capilar, coloração de mucosa, grau de desidratação, temperatura retal), avaliação locomotora (dores musculares e claudicação). Após liberação veterinária, o animal recebeu água e feno à vontade por um período de 40 minutos. Depois desse período, o animal foi recolocado na esteira e submetido a novo anel. $\mathrm{O}$ animal que apresentava frequência cardíaca superior a $60 \mathrm{bat} / \mathrm{min}$ ) foi monitorado por um período de até 20 minutos, até a frequência cardíaca atingir 60 bat/min para seguir para exame. Caso isso não ocorresse, o animal era retirado da prova. Dos 20 animais submetidos ao enduro em esteira rolante, apenas 5 não concluíram a prova. Esses cinco cavalos nunca tinham sido submetidos ao treinamento para enduro, fator que pode ter contribuído para a não-conclusão da prova. Possivelmente, se houvesse continuidade no treinamento, esses animais concluiriam a simulação de prova de enduro. Para mensuração da atividade das enzimas CK, AST e LDH, o sangue foi colhido imediatamente após o exercício, por venopunção da jugular esquerda em tudo vacutainer, o qual foi mantido armazenado em recipiente resfriado até ser centrifugado. Amostras de sangue foram colhidas antes do início do exercício (basal) e ao final de cada anel do enduro (20, 40, 60 e $80 \mathrm{~km}$ ). O soro foi separado e armazenado em ependorfes ${ }^{\circledR}$. A atividade enzimática foi determinada em kits bioquímicos da empresa Labtes ${ }^{\circledR}$ com leitura em espectrofotômetro Labquest ${ }^{\circledR}$.

Após a simulação do enduro em esteira rolante, o animal foi mantido em observação veterinária, recebeu duchas e permaneceu estabulado por 24 horas recebendo somente feno à vontade e água fresca. Após 24 horas, foi solto no pasto.

A análise estatística foi realizada utilizando-se a metodologia de Modelos Lineares Generalizados descrito por Nelder \& Weddeburn (1972). Considerando que os dados apresentaram distribuição " $\gamma$ " com função de ligação logarítima, as esperanças para as variáveis independentes foram modeladas conforme a expressão: $\mathrm{E}(\mathrm{Y})=\mathrm{e}^{\eta}$, em que $\eta=\mu+T_{i}+D_{j}+D T_{i j}+A_{k} / T_{i}$, em que: $\mu=$ constante geral, $\mathrm{T}_{\mathrm{i}}=$ efeito do nível de óleo de soja no concentrado i , $\mathrm{i}=0$, 6, 12, 18, 24\% de óleo; Dj = efeito da distância da prova j, $\mathrm{j}=0,20,40$, 60 e $80 \mathrm{~km}$; DTij = efeito da interação entre distância percorrida nível de inclusão de óleo de soja e $\mathrm{Ak}=$ efeito do animal em cada nível de óleo de soja.

Os efeitos do óleo de soja e da distância foram desdobrados em efeitos lineares, quadráticos e cúbicos para estabelecer o modelo de superfície de resposta.

\section{Resultados e Discussão}

Neste estudo a aplicação do modelo linear generalizado foi atribuída à grande variação nos valores de atividade enzimática, tanto entre animais do mesmo nível de óleo como entre os níveis de óleo, fazendo com que os dados não apresentassem distribuição normal. Na maior parte dos trabalhos consultados, foi ignorada essa variação, ou seja, os dados foram analisados como se apresentassem comportamento normal, o que pode ter ocasionado interpretações equivocadas sobre os dados obtidos.

Neste trabalho foi observado efeito $(\mathrm{p}<0,05)$ do óleo e da distância percorrida para as variáveis, LDH e (6,624- $^{(6,6)}$ $0,3522 x+0,03448 x 2-0,0008382 x 3+0,02401 z-0,0007489 x z) \quad C K$ e $(8,06-, 07020 x+0,05546 x 2-0,001262 x 3+0,01204 z+0,0006207 x z)$ e $\operatorname{AST} \mathrm{e}^{(7,045-0,2292 \mathrm{x}+0,007991 \mathrm{x} 2+0,008517 \mathrm{z}-0,0003282 \mathrm{xz}}$ (Figura 1).

A adição de óleo de soja teve efeito cúbico sobre as atividades plasmáticas das enzimas LDH e CK, assim como efeito linear para a distância percorrida. Na distância percorrida de 40 e $80 \mathrm{~km}$ nos animais alimentados com a dieta controle, houve grandes aumentos de atividade enzimática.

Considerando que, no ponto de $40 \mathrm{~km}$ percorridos, o animal estava adaptando seu organismo ao aumento da demanda energética, os aumentos plasmáticos de LDH indicam que houve aumento na conversão de piruvato a lactato e esse aumento foi reforçado pelas concentrações de lactato observadas neste trabalho (Figura 2).

Neste experimento, a partir dos $40 \mathrm{~km}$, houve aumento da concentração de lactato, comprovando maior atividade anaeróbica. Entretanto, como esse aumento não foi exponencial, pode-se considerar que as isoenzimas agem de forma diferente sobre o metabolismo. Considerando a afirmação de Favero et al. (1999), pode-se sugerir que, em animais adaptados ao exercício, existe grande contribuição da H-LDH na musculatura do animal, o que foi evidenciado pelos dados obtidos neste experimento pelo crescimento não-exponencial do lactato.

Hodgson et al. (1985) observaram maior capacidade oxidativa das fibras do tipo IIB atribuídas ao exercício, bem como retardamento no recrutamento dessas fibras, uma vez que as fibras musculares são recrutadas na respectiva sequência: tipo I, tipo IIA e tipo IIB (Snow, 1981). Considerando essa sequência de recrutamento anteriormente 

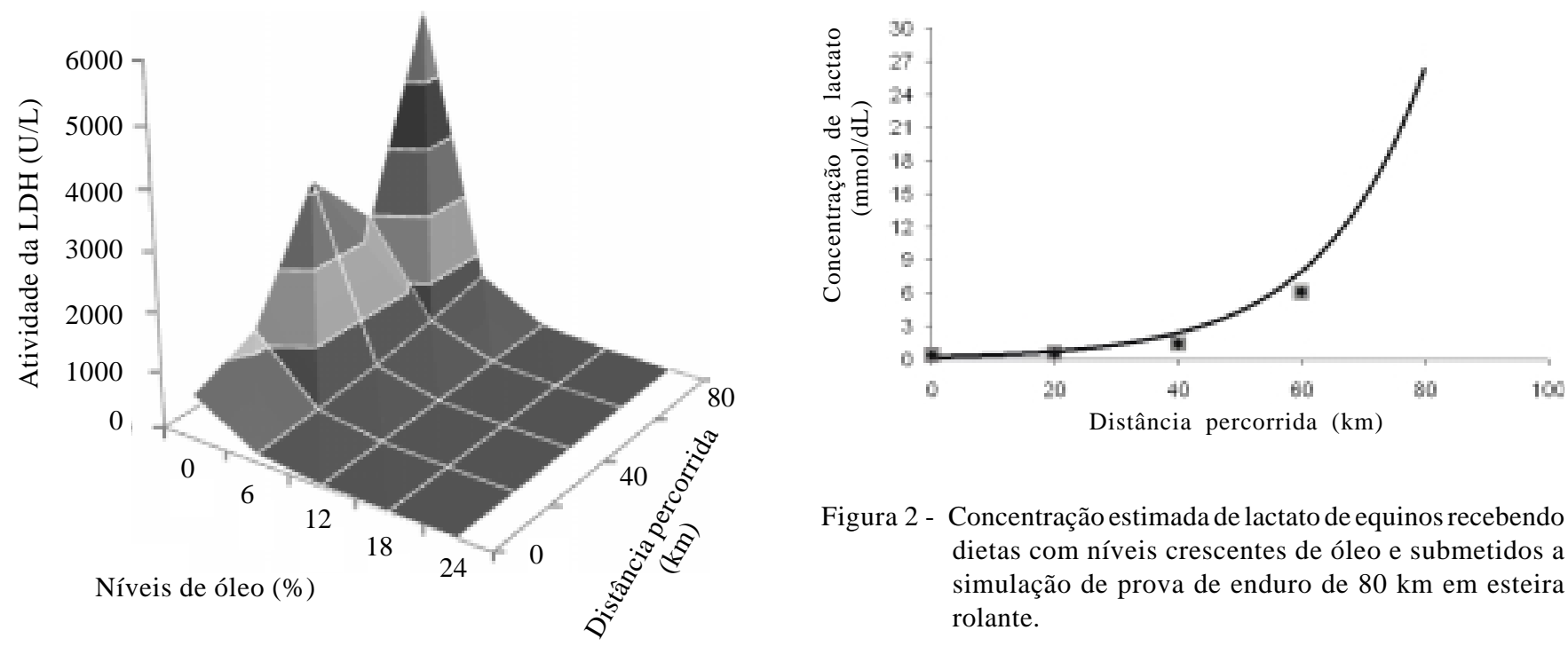

Figura 2 - Concentração estimada de lactato de equinos recebendo dietas com níveis crescentes de óleo e submetidos a simulação de prova de enduro de $80 \mathrm{~km}$ em esteira rolante.

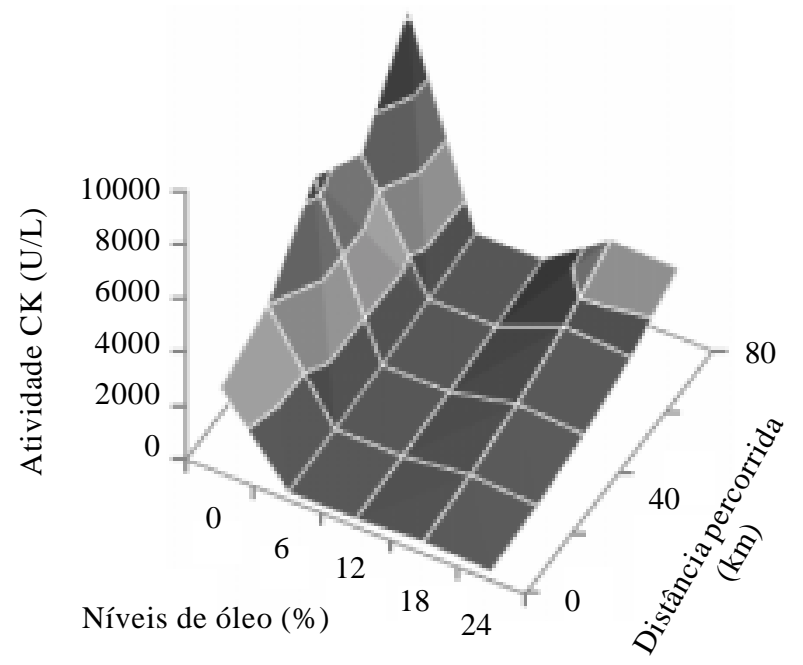

citada, é possível que, a partir dos $40 \mathrm{~km}$, as fibras do tipo IIB tenham sido requeridas para o exercício, indicando as maiores atividades enzimáticas a partir deste ponto. Alguns autores sugeriram que a LDH e a CK apresentam maiores concentrações nas fibras do tipo IIB e, como elas são mais requeridas a partir de $40 \mathrm{~km}$, as atividades plasmáticas seriam maiores. Ao longo do exercício, neste estudo, ocorreu aumento nos níveis de lactato e, com isso, sugere-se aumento na geração de íons hidrogênio. Esses íons hidrogênio, por sua vez, favoreceram a corrente de prótons na membrana da mitocôndria desencadeando todos os processos intramitocondriais, sobretudo a fosforilação oxidativa, como previamente observado por Korzeniewski \& Zoladz (2003). O aumento de íons-hidrogênio pode também ter favorecido a atividade da CK neste trabalho, pois ela depende da presença desses íons para sua atividade e favorece a manutenção da homeostasia celular pelo controle do $\mathrm{pH}$, atribuída à sua capacidade tampão, como citado por Bendahan et al. (2003).

Como a atividade da LDH aumentou, houve desbalanço na relação NADH:NAD, favorecendo a fosforilação oxidativa, quetambém é estimulada pela crescente geração de $\mathrm{H}^{+}$e ADP observada com o aumento da atividade muscular, refletida neste experimento pelo aumento das atividades plasmáticas das enzimas avaliadas.

Neste experimento, houve queda nas atividades enzimáticas com a adição de óleo nas dietas. Quando o óleo é adicionado à dieta, as rotas metabólicas são redirecionadas para a $\beta$-oxidação, como relatado por Hodgson et al. (1985) e Gleen et al. (2001), que citaram várias adaptações na musculatura favorecendo a utilização do óleo como fonte energética. Neste experimento, há indicações de que a rota metabólica predominante foi a oxidação lipídica, pois não foi observado aumento exponencial do lactato nem 


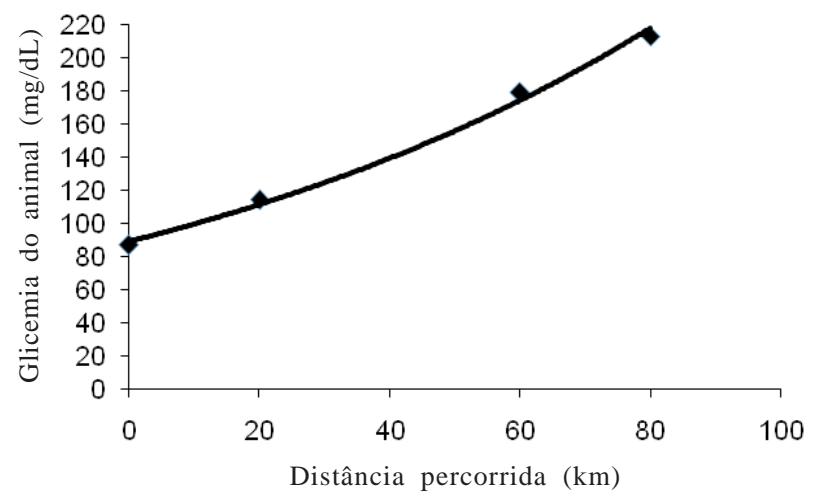

Figura 3 - Glicemia estimada de equinos recebendo dietas com níveis crescentes de óleo e submetidos à simulação de prova de enduro de $80 \mathrm{~km}$ em esteira rolante.

aumento na glicemia ao longo da distância percorrida (Figuras 2 e 3).

A queda da atividade plasmática de LDH neste experimento com o fornecimento de óleo indica menor utilização do glicogênio muscular, confirmando o relatado por outros pesquisadores, como Harkins et al. (1992) e Hambleton et al. (1980). A predominância da $\beta$-oxidação pode ser explicada por Hiney \& Potter (1996), que citaram que o aumento na oxidação de ácidos graxos causa aumento na produção de acetil CoA, o qual inibirá a enzima piruvato desidrogenase, aumentando a concentração de piruvato e diminuindo a importância da glicólise para a geração de energia. Como a produção de acetil CoA é constante, o ciclo de Krebs apresenta substrato para sua utilização, favorecido pelo aumento crescente nas concentrações de ADP e pela queda na relação NADH: NAD.

Considerando o observado neste experimento, o aumento da atividade da LDH incrementou a geração de NAD enfatizando a fosforilação oxidativa. O desbalanço de NADH:NAD, bem como a maior disponibilidade de substrato (acetil-CoA), favoreceu a atividade da lançadeira de malato, na qual a enzima AST participa ativamente (Figura 1).

Semelhante ao ocorrido com as atividades plasmáticas das enzimas CK e LDH, maiores valores plasmáticos de atividade enzimática da AST foram observados nos animais alimentados com a dieta controle (sem adição de óleo) deste experimento. Como neste grupo o metabolismo foi predominantemente glicolítico, o ciclo de Krebs é ativo utilizando piruvato proveniente da glicólise. Com o desvio metabólico observado com a adição de óleo, o piruvato gerado na glicólise poderia ser direcionado para a geração de intermediários de rota e, assim, o piruvato seria redirecionado para a formação de oxaloaceto e este, por sua vez, formaria malato, poupando atividade da lançadeira de malato, refletida pela menor atividade plasmática da enzima AST.

Segundo Korzeniewshi \& Zoladz (2003), na presença de oxigênio e pela adaptação ao exercício, a creatina fosfato pode fornecer energia até cerca de 30 segundos do exercício, fato que pode ter ocorrido no grupo controle deste experimento, favorecendo a presença de maiores atividades enzimáticas.

Quando o metabolismo vigente é o glicolítico, a importância da CK aumenta, ressaltando seus elevados valores plasmáticos. Segundo Bendahan et al. (2003), a glicólise é um importante repositor energético para que a síntese da creatina fosfato ocorra no músculo. Desta forma, no grupo controle, a ressíntese rápida da creatina fosfato possibilitou a reutilização dessa via e influenciou o aumento da atividade plasmática da $\mathrm{CK}$.

\section{Conclusões}

O óleo é uma importante e bem aproveitada fonte de energia para equinos em exercício. A adição de óleo à dieta de animais de enduro e o treinamento adequado dos animais promovem alteração metabólica que favorece a produção de energia. A menor atividade plasmática das enzimas aspartato aminotransferase, cratina quinase e lactato desidrogenase com a adição de óleo de soja comprovou o direcionamento do metabolismo energético para a oxidação lipídica. Como apresentam várias isoenzimas, essas enzimas atuam amplamente no metabolismo energético, favorecendo a constante reposição de ATP ao longo do exercício, bem como o consumo de lactato (catabólito) mediado pela lactato desidrogenase.

\section{Referências}

BALDARI, C.; GUIDETTTI, L.A. Simple method for individual anaerobic threshold as predictor of max lactate steady state. Medicine \& Science in Sport \& Exercise, v.32, n.10 p.1798-2000, 2000.

BALDISSERA, V. Fisiologia do exercício para eqüinos. Caderno Técnico da Escola de Veterinária da UFMG, v.21, p.39-57, 1997.

BENDAHAN, D.; KEMP, G.J.; ROUSSEL, M. et al. ATP synthesis and proton handling in muscle during shot periods of exercise and subsequent recovery. Journal Applied Physiology, v.94, p.2391-2397, 2003.

FAVERO, T.G.; STAVRIANEAS, S.; KLUG, G.A. Training-induce alterations in lactate dehydrogenase reaction kinetics in rat: a re-examination. Experimental Physiology, v.84, p.989-998, 1999.

FRAPE, D.L. Diet and exercise performance in the horse. Proceeding of the Nutrition Society, v.53, p.189-206, 1994

GLEEN, N.J.; BLAZQUEZ, C.; GLEEN, M.J.H. et al. High fat intake lowers hepatic fatty acid synthesis and raises fatty acid oxidation in aerobic muscle in shetland ponies. British Journal of Nutrition, v.86, p.31-36, 2001. 
HAMBELTON, P.L.; SLADE, L.M.; HAMAR, D.W. et al. Dietary fat and exercise conditioning effect on metabolic parameters in the horse. Journal of Animal Science, v.51, n.6, p.1330-1339, 1980.

HARKINS, J.D.; MORRIS, G.S.; TULBY, R.T. et al. Effect of added fat on racing performance in thoroughbred horse. Journal Equine Veterinary Science, v.12, n.2, p.123-129, 1992.

HARPER, H.A. Manual de química fisiológica. São Paulo: Atheneu, 1977. 13p.

HINEY, K.M.; POTTER, G.D. A review of recent research on nutrition and metabolism in the athletic horse. Nutrition Research Reviews, v.9, p.149-173, 1996.

HODGSON, D.R.; ROSE, R.J.; Di MAURO, J. et al. Effects of a submaximal treadmill training program on histological properties, enzyme activies and glycogen utilization of skeletal muscle in the horse. Equine of Veterinary Journal, v.17, p.300-3005, 1985.

KORZENIEWSHI, B.; ZOLADZ, J.A. Training-induced adaptation of oxidative phosphorylation in skeletal muscle. Biochemical Journal, v.374, p.37-40, 2003.

NATIONAL RESEARCH COUNCIL - NRC. Nutrient requirements of horses. Washington, D.C.: National Academy of Sciences, 1989. 100p

NELDER, J.; WEDDEBURN, R.W. Generalized linear models. Journal of Royal Statistic Society, v.135, p.370-384, 1972.
PAGAN, J.D.; ESSEN-GUSTAVSSON, B.; LINDHOLM, A. et al The effect of dietary energy source on exercise performance in Standardbred horses. In: GILLESPIE, J.R.; ROBINSON, W.E. (Eds.) Equine exercise physiology 2. Davis: ICEEP Publications, 1987. 686p.

PAGAN, J.D. Responses of blood glucosa, lactate and insulin in horses fed equal amounts of grain with or without added soybean oil. In: RECETS ADAVANCES IN EQUINE NUTRITION, 1995, Kentucky. Proceedings... Kentucky: Kentucky Equine Research, 1995. p.57-60.

SAKS, V.A.; KONGAS, O.; VENDELIN, M. et al. Role of the creatine/phosphocreatine system in the regulation of mitochondrial respiration. Acta Physiology Scand, v.168, p.635-641, 2000.

SNOW, D.H. Muscle fibre composition and glicogen depletion in horses competing in na ride. Veterinary Record, v.108, p.374-378, 1981.

TEGBUR, U.; BUSSE, M.W.; BRAUMANN, O. Estimation of an individual equilibrium between lactate production and catabolism during exercise. Medicine Science Sports Exercise, v.25, p.620-627, 1993

YAMASHITA, K.; YOSHIKA, T. Profiles of creatine Kinase isoenzyme compositions in single muscle fibres of different types. Journal of Muscle research and Cell Motility, v.12, n.1, p.37-44, 1991. 